\title{
LIENZOS DE JOSÉ MORENO PARA EL RETABLO DEL SANTO CRISTO DE LA SANGRE DE TORRIJOS (TOLEDO)
}

Continuación de los estudios del autor sobre la biografía y la obra de José Moreno (Madrid, c 1630/1637 - Burgos, 1677). Da a conocer y estudia los tres lienzos desconocidos del retablo mayor del Hospital del Santo Cristo de la Sangre de Torrijos (Toledo), pintados en 1667.

Palabras clave: Pintura española; Escuela de Madrid; Barroco; Siglo XVII; José Moreno; Torrijos.

In this article the author continues his studies of the life and work of José Moreno (Madrid, c. 1630/1637 - Burgos, 1677). Three unknown canvases from the altarpiece of the Hospital del Santo Cristo de la Sangre of Torrijos (Toledo), painted in 1667 , are here presented and studied.

Key words: Spanish Painting; School of Madrid; Baroque; 17th century; José Moreno; Torrijos.

El hospital de la Santísima Trinidad de Torrijos (Toledo) es una venerable fundación patrocinada por los señores de Maqueda, don Gutierre de Cárdenas (? - Alcalá de Henares, 1503) y su mujer doña Teresa Enríquez (Valladolid, hacia 1450 - Torrijos, 1529), hija natural del Almirante de Castilla ${ }^{1}$. De él se conservan hoy un patio renacentista y la iglesia, que básicamente se erigió sobre el espacio de una antigua sinagoga, a la que se añadió a lo largo del primer tercio del siglo XVI una cabecera gótica poligonal de cinco paños que conforma en la actualidad el presbiterio. Presenta una nave única con dos importantes adicciones en las que tienen cabida, por el lado sur, la sacristía y la capilla de Santa Ana, con ornamentación geométrica de estilo clasicista; y, por el lado este, un camarín adosado a la cabecera, obra de la segunda mitad del siglo XVIII. De menor empaque arquitectónico es la capilla de la Soledad que se abre en el muro norte. Vinculada a la familia Cebreros, para este reducido espacio y para la Hermandad de la Preciosa Sangre de Nuestro Señor Jesucristo don Francisco de Cebreros envió desde Méjico la imagen del Santo Cristo de la Sangre, una importante obra de escultura hispanoamericana, cuyo estilo y técnica la emparenta con otras imágenes semejantes realizadas en lo fundamental a base de caña y pasta de maíz ("pasta de Michoacán"), a la que se añaden colas y papel, además de los pigmentos de policromía y los aceites para el abrillantado final. El resultado final son imágenes de tamaño natural y escaso peso, lo que facilita enormemente su traslado ${ }^{2}$.

El culto a la imagen del Santo Cristo de la Sangre fue creciendo, especialmente después de que en 1711 la Hermandad del Santísimo Cristo de la Sangre se escindiera de la Preciosa Sangre, arrastrando con ella a la imagen y a sus devotos ${ }^{3}$. Experimentó un nuevo auge a mediados del siglo XVIII, buscándose por entonces el reconocimiento canónico de varios milagros y realizando varias obras en la iglesia que se centraron fundamentalmente en la decoración pictórica del presbiterio y en la construcción del camarín (hacia 1765), ésta promovida por doña Ana de Silva Sarmiento, duquesa de Arcos, Maqueda, Nájera y Baños ${ }^{4}$, que conllevó la reforma del cuerpo principal del retablo para permitir la contemplación del Santo Cristo de la Sangre desde la iglesia.

Los andamios colocados para la reciente restauración de la iglesia (2007-2008), centrada en la limpieza de la bóveda, que ha desvelado un conjunto pictórico de ángeles pasionarios y motivos ornamentales, y en las pinturas murales de los paños laterales del presbiterio, también ha permiti-

${ }^{1}$ Castro y Castro, Manuel de: o.f.m. La loca del Sacramento y Gutierre de Cárdenas. Toledo, 1992. Longobardo Carrillo, Julio; SÁnchez de Haro, Jesús; Peña Carbonero, Justiniano de la; Buttrago Maselli, Javier y Alcántara GARCíA, Fernando: Cofradías y Hermandades en la Villa de Torrijos. Toledo, 2008, pp. 89-94.

${ }^{2}$ La de Torrijos mide 2,02 metros de alta y pesa poco más de 8 kilos (Longobardo Carrillo et alii, op. cit., 2008, p. 109).

3 Longobardo Carrillo, J. et alii, op. cit., p. 95.

${ }^{4}$ Ibidem, pp. 103 y 144. La misma duquesa encargó a Juan Fernando Palomino en 1779 una plancha para imprimir estampas que representa el retablo del Santo Cristo rodeado de varias escenas con milagros. LongobARDo CARRILLO, Julio; Peña Carbonero, Justiniano de la; Buttrago Maselli, Javier y Alcántara García, Fernando: Cofradias y Hermandades en la Villa de Torrijos. Toledo, 2005. 
do contemplar de cerca y comprobar que la pintura de la Santísima Trinidad que corona el ático del retablo barroco está firmada por el pintor madrileño José Moreno y fechada en 1667. Por su estilo, también pueden atribuirse a Moreno los pequeños lienzos de San Miguel arcángel y de San Agustín que decoran las partes altas de las calles del evangelio y de la epístola respectivamente ${ }^{5}$.

Los tres lienzos se enmarcan en un retablo de estilo barroco, realizado en madera dorada, compuesto por un sotabanco con banco, un cuerpo y un ático en remate semicircular, y estructurado en tres calles mediante columnas salomónicas ceñidas por sarmientos de vid. Aunque no debió de ser así en origen, hoy la calle central se abre en arco rebajado hacia el camarín del siglo XVIII para permitir el acceso visual a la imagen del Santo Cristo de la Sangre que preside el retablo. Por curioso que parezca, se desconoce cual fue la imagen que originariamente presidió este retablo. Debió de ser un Ecce Homo, un Cristo atado a la columna u otro Crucificado, pues la policromía seiscentista de las jambas de la hornacina luce emblemas de la pasión. Entre las columnas de las calles laterales hay repisas con esculturas que se identifican comúnmente con San Pedro y San Pablo, si bien carecen de atributos evidentes y la supuesta de San Pedro lleva vestiduras de San Nicolás de Bari. En su parte alta hay dos lienzos casi cuadrados de San Miguel y San Agustín, que a lo largo del siglo XX han cambiado de ubicación, según puede apreciarse en algunas fotografías antiguas. En el ático, la decoración está compuesta por un lienzo de la Santísima Trinidad entre los lunetos con decoración de roleos vegetales del medio punto.

Aun cuando la fundación del hospital se hizo bajo la advocación de la Santísima Trinidad, la creciente devoción al Santo Cristo de la Sangre explica el resto de la decoración del presbiterio, en cuya bóveda han quedado al descubierto unos gruesos angelotes barrocos e instrumentos de la pasión de Cristo. Los muros presentan unas vistosas pinturas murales con grandes perspectivas arquitectónicas que los horadan visualmente y los abren a través de balaustradas hacia el exterior. Entre sus columnas y escalinatas se pintaron escenas de la pasión de Cristo, algunas completamente perdidas, de modo que hoy sólo se pueden apreciar las escenas del Ecce Homo en el lado del evangelio y la de Cristo camino del Calvario se encuentra con su madre, en el lado de la epístola; e intuir otras a través de figuras fragmentarias como la Flagelación. En el luneto sobre la escena del Ecce Homo se identifica a San Juan Evangelista, resto de un conjunto de evangelistas, muy deteriorados, que también formaron parte de este conjunto iconográfico de argumento pasionario acorde con la devoción al Santo Cristo.

Estas pinturas murales presentan un estilo ampuloso y escenográfico, distinto del de los lienzos de José Moreno y muy propio del Barroco de la primera mitad del siglo XVIII, periodo a lo largo del cual debieron realizarse.

De los tres lienzos de José Moreno el más importante es sin duda el de la Santísima Trinidad (fig. 1), que presenta en el borde inferior derecho una firma semioculta bajo la moldura del retablo en la que con la fotografía a la vista hecha desde el andamio de la restauración sólo es posible leer: " $J^{h p}$ moreno, $f^{t}, / \ldots 667$ ", siendo probable que también conste en ella la expresión "año de" y el número uno (1) correspondiente al millar. No fue posible tomar sus medidas, debido a que el andamio estaba despegado del plano del retablo, pero se trata de un lienzo de grandes proporciones, en estado intacto, con un bastidor original muy ligero, cuyo formato horizontal queda visualmente delimitado, aunque no cortado, por el trazado curvilíneo de las molduras del arco y del remate del retablo. En un escenario de gloria cuajado de nubes de color blanquecino dorado Moreno trazó una composición simétrica con la paloma del Espíritu Santo en el centro, flanqueada por las figuras de Dios Padre y de Cristo resucitado, ambos sentados, con cetros y acompañados por ángeles con globos terráqueos cristalinos. La pintura demuestra perfectamente el estilo de Moreno, tanto en el dibujo ondulante de los contornos de las figuras, como en la ca-

\footnotetext{
5 Agradezco a Jesús Sánchez de Haro la comunicación del hallazgo y la ocasión de estudiar estas pinturas.
} 


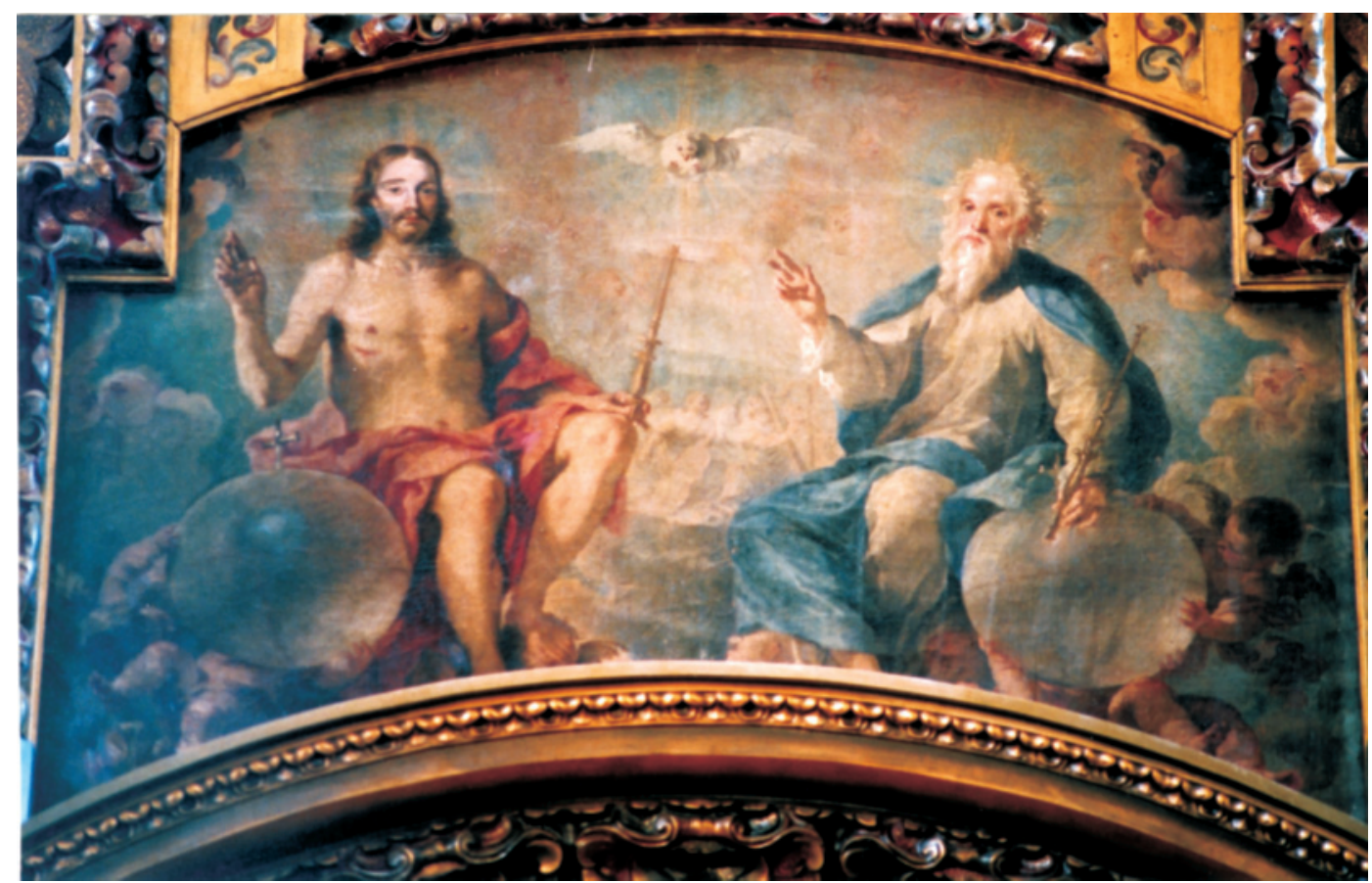

Fig. 1. José Moreno. Santísima Trinidad. Firmado. 1667. Torrijos (Toledo). Iglesia del Santo Cristo de la Sangre.

racterización fisonómica de las figuras o en el colorido suave, dominado por tonos nacarados para la anatomía del desnudo de Cristo y los blancos, azules y carmines rosáceos para las vestimentas de las figuras. La facilidad que Moreno mostró en toda su obra se aprecia en el modo de resolver con pinceladas redondeadas y ampulosas la forma del Espíritu Santo, semejante a las palomas que aparecen en otras pinturas suyas. La cabeza de Dios Padre es semejante a la de Zacarías de la Visitación que fechó en 1662 (Madrid, Museo Nacional del Prado) ${ }^{6}$.

La pintura es un excelente ejemplo del quehacer de los pintores jóvenes de la escuela de Madrid en la década de 1660, atentos tanto a la asimilación de las novedades técnico-estilísticas flamencas y venecianas, como a su interpretación por los grandes pintores del momento como Francisco Herrera el Mozo, Francisco Rizi y Juan Carreño de Miranda. En este sentido, aunque la pintura de Moreno en su interpretación esencial del tema de la Trinidad pueda evocar la Trinidad pintada por Antonio de Pereda hacia 1659 para el ático del retablo mayor del Carmen Calzado de Madrid (hoy parroquia del Carmen y San Luis de Madrid) ${ }^{7}$, en realidad guarda estrecha relación con una de las más famosas pinturas del momento como es la Fundación de la Orden de la Santísima Trinidad o Primera misa de San Juan de Mata (París, Museo del Louvre), obra concluida por Carreño de Miranda en 1666. Este cuadro destinado a los Trinitarios de Pamplona contó con una gestación compleja, fruto de la feliz colaboración entre Francisco Rizi y el propio Carreño de Miranda, y perfectamente documentada gracias a la existencia de un dibujo previo de Rizi

\footnotetext{
${ }^{6}$ GutiÉRrez PAstor, Ismael: "El pintor José Moreno (c. 1630/1637-1677): revisión de su vida y nuevas obras”, en Anuario del Departamento de Historia y Teoría del Arte (Universidad Autónoma de Madrid), vol. XVII, 2005, p. 71, fig. 3.

7 Angulo IÑiguez, Diego y PÉrez SÁnchez, Alfonso E.: Historia de la Pintura española. Escuela madrileña del segundo tercio del siglo XVII. Madrid, 1983, p. 198, n. ${ }^{\circ} 91$ y lámina 204.
} 
(Florencia, Uffizi) y de un boceto de Carreño (Viena, Academia de Bellas Artes) ${ }^{8}$. Puede que Moreno conociera el boceto de Viena o que viera el cuadro destinado a los Trinitarios de Pamplona, pero la composición de la Santísima Trinidad del Santo Cristo de la Sangre de Torrijos se atiene al dibujo de Rizi en el significativo detalle de disponer erguida la cabeza de Dios Padre. Quiere esto decir que uno o dos años después de que el proyecto para los Trinitarios de Pamplona se hubiera concretado en el dibujo y en el boceto citados (hacia 1665-1666), José Moreno volcó parte de sus enseñanzas en la Santísima Trinidad (1667) del retablo de Torrijos, interpretándolas con un estilo plenamente barroco y un colorido cristalino.

Los lienzos de San Miguel arcángel y San Agustín ${ }^{9}$ (figs. 2 y 3) son obras de carácter menor y a simple vista no parece que estén

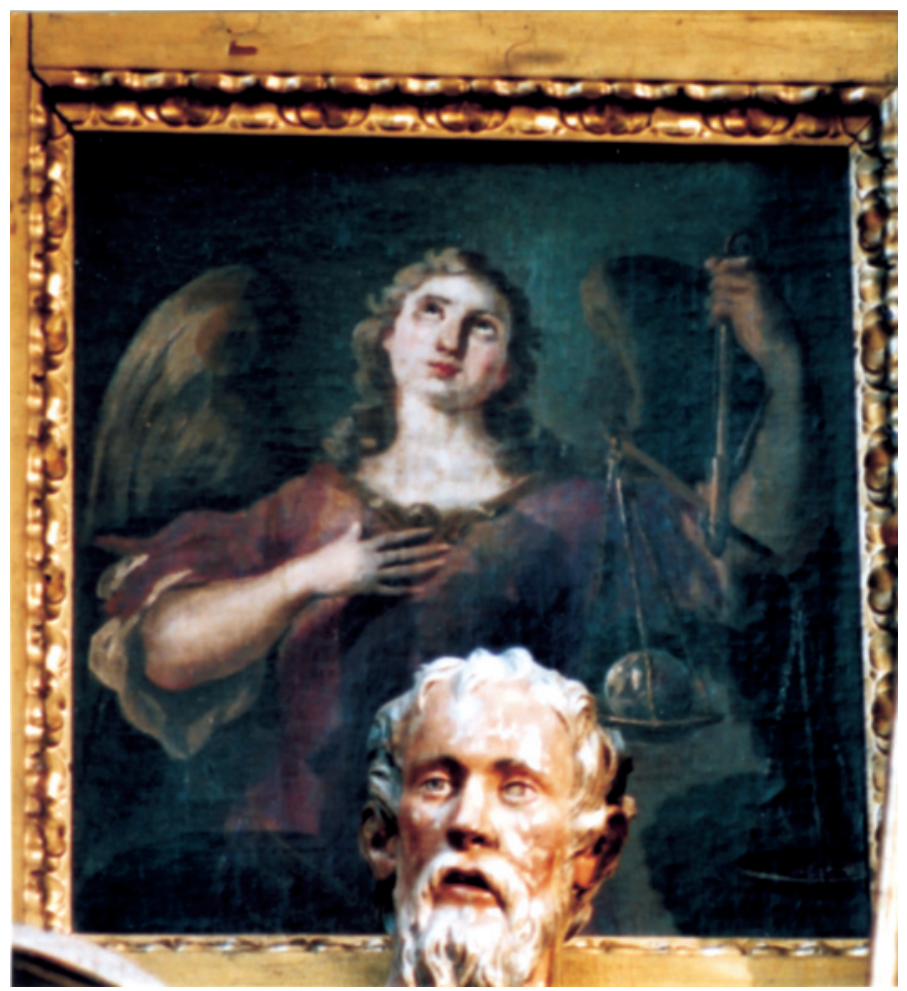

Fig. 2. José Moreno. San Miguel arcángel. Torrijos (Toledo). Iglesia del Santo Cristo de la Sangre. firmadas. No obstante, sus modelos humanos denotan el refinado sentido del color y la delicadeza del estilo de José Moreno. Ambas vienen a completar un sencillo programa iconográfico sobre el misterio de la Santísima Trinidad, titular del hospital, y en este sentido es ajeno a la presencia del Santo Cristo de la Sangre, aunque no a cualquier otra imagen de Cristo. En el lado del evangelio se representa a San Miguel arcángel de frente, con las alas explayadas y la vista hacia lo alto como buscando a la Trinidad situada en el ático. Lleva en la mano izquierda una balanza con los platillos descompensados, cargados con una especie de esferas poco definidas, pero con las que evidentemente se alude al juicio final y al peso de las almas y de los méritos contraídos por los hombres en la tierra, con el consiguiente castigo o premio en la vida eterna, cuyo final cristiano es la contemplación de Dios uno y trino en la gloria.

La correspondencia espacial dentro del retablo entre la posición en lo alto de la Santísima Trinidad y la vista elevada de San Miguel arcángel no es tan clara en el caso del lienzo de San Agustín, colocado en el lado de la epístola, representado lateralmente y con la vista hacia lo alto, pero hacia fuera del retablo, de modo que hoy su mirada se dirige hacia la luz natural de los ventanales del muro sur de la iglesia. La explicación está en algunas fotografías antiguas, en las que imágenes y cuadros se ven cambiados de lado $^{10}$. El santo está caracterizado como obispo de Hipona, con

\footnotetext{
8 Véanse las tres imágenes en Pérez SÁnchez, Alfonso E.: Carreño, Rizi, Herrera y la pintura madrileña de su tiempo (1650-1700), catálogo de la exposición, Madrid, Museo del Prado, Palacio de Villahermosa, 1986, p. 42 (dibujo de Rizi), p. 43 (lienzo del Louvre) y p. 208 (boceto de la Academia de Viena).

${ }_{9}$ Óleos sobre lienzo, con respaldo de tabla, $54 \times 48 \mathrm{~cm}$.

${ }^{10}$ Véase alguna de estas fotografías en el libro de LONGOBARdo CARrillo et alii, op. cit., 2008, p. 100.
} 


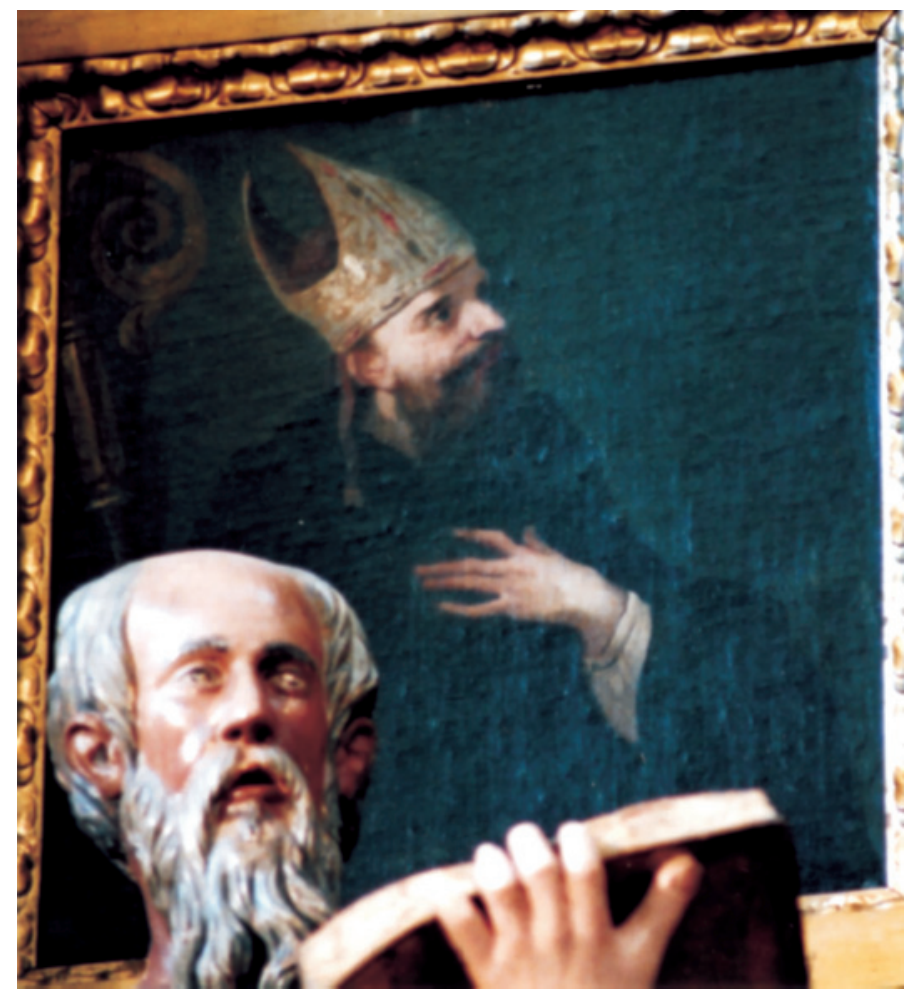

Fig. 3. José Moreno. San Agustín. Torrijos (Toledo). Iglesia del Santo Cristo de la Sangre. mitra, báculo y hábito negro, de modo que el mayor interés de la composición queda centrado en la viveza del gesto y en la fina mano sobre el pecho. La presencia de San Agustín en el contexto iconográfico del retablo tiene que ver con sus esfuerzos intelectuales por comprender el misterio de la Santísima Trinidad y de sus tres personas distintas (Padre, Hijo y Espíritu Santo) en un sólo Dios verdadero, esfuerzos expresados en su tratado De Trinitate $^{11}$.

Por su fecha, los lienzos del retablo del Santo Cristo de la Sangre de Torrijos se sitúan entre los más antiguos conocidos de José Moreno y en un periodo de grandes discontinuidades cronológicas en la vida y obra del pintor. Les precede una Adoración de los Reyes Magos, fechada en 1660 (colección particular), y la Visitación de 1662 (Madrid, Museo Nacional del Prado) ${ }^{12}$.

Gracias a que el lienzo de la Santísima Trinidad está fechado

en 1667 se puede pensar que el retablo mayor se construyó poco antes, siendo el dorado del retablo y los lienzos de Moreno la culminación de esta fase de embellecimiento de la iglesia.

José Moreno (¿Madrid?, hacia 1630/1637 - Burgos, 1677) fue un refinado pintor madrileño de la segunda mitad del siglo XVII ${ }^{13}$. Por los documentos que conservamos sobre su vida y obra, debió de nacer en Madrid, donde residían y tenían casa propia sus padres, el ensamblador Felipe Moreno y su segunda mujer Hipólita del Castillo, casados hacia 1627 o 1628, pues, según se deduce del testamento de Felipe redactado en 1652, en éste último año fue bautizado su hijo Juan, hermano del pintor. Juan siguió la carrera militar, sirvió al rey Felipe IV en la guerra de Cataluña y cuando su madre hizo testamento en 1665 no se tenían noticias suyas, de modo que José vino a quedar como único heredero de su madre y de las casas que por línea paterna la familia tenía en la Puerta del Sol de Madrid.

Aunque Palomino señala a Francisco de Solís como su maestro ${ }^{14}$, es poco lo que se sabe de su formación como pintor, a excepción de que su madre nombró al pintor Juan Montero de Rojas y al grabador Gregorio Fosmann como testamentarios junto con su propio hijo. Pero el estilo de Moreno no puede vincularse al de Montero de Rojas, siendo más bien reflejo del complejo

11 Félix García, O.S.A. "28 de agosto. San Agustín”, en Echeverría, Lamberto de y LlorCA, Bernardino S.I., Año cristiano, III, julio-septiembre. Madrid, Biblioteca de Autores Cristianos, 1966 (segunda edición), pp. 488-498.

12 Gutiérrez Pastor, op. cit., p. 71.

13 Para todo lo relativo a la biografía revisada y a la obra de Moreno, véase mi artículo citado en nota 2.

14 Palomino de Castro y Velasco, Antonio: El Museo pictórico y la escala óptica (1726). Madrid, edic. Aguilar, 1947, p. 976. 
mundo de influencias de la escuela de Madrid, guiada por los grandes maestros Juan Carreño de Miranda, Francisco Rizi y Francisco de Herrera el Mozo, y seguida por un nutrido grupo de cualificados discípulos que en muchos casos fallecieron muy jóvenes. Uno de ellos podría haber sido José Moreno, que al morir podía tener entre 37 y 30 años aproximadamente. El colorido claro de su pintura, con delicados tonos malvas, grises plateados y carmines, los efectos de profundidad conseguidos con los contrastes de luz y sombra, y los plegados amplios recuerdan en ocasiones el estilo de su contemporáneo Juan Antonio Frías y Escalante.

Por una errónea información antigua de Antonio Palomino se venía considerando que José Moreno había nacido en Burgos ${ }^{15}$. No fue así, aunque el pintor se trasladó a la ciudad castellana en 1674 y residía en ella cuando en 1677 otorgó varios documentos de donación y de testamento poco antes de morir a finales de dicho año. Las razones del traslado a Burgos no están completamente claras. En 1674 realizó para los frailes Dominicos del convento de San Pablo cuatro lienzos para dos retablos de su iglesia, firmados en dicho año y parcialmente conservados en la parroquia de Quintanadueñas (Burgos) ${ }^{16}$. Por el codicilo de 3 de noviembre de 1677 se sabe que Moreno mantuvo su actividad profesional en Burgos, realizando varios encargos para clientes particulares ${ }^{17}$. Unos meses antes, el 30 de mayo de 1677 había hecho donación de las casas de la Puerta del Sol de Madrid a los frailes Franciscanos Mínimos del convento de la Victoria de la Villa y Corte, obligándose éstos a dar al pintor una renta vitalicia de 1.200 reales anuales y a fundar una memoria de dos misas semanales que debía ser trasladada allí donde muriera el donante y donde los Franciscanos Mínimos le dieran sepultura. Falleció Moreno después del 3 de diciembre de 1677, día en que dio poder a los Mínimos de Madrid para cobrar las rentas vencidas de las casas madrileñas, y dentro de dicho mes según consta por una diligencia del escribano burgalés José Gutiérrez del Campo. El óbito ocurrió en el hospital de la Concepción de Burgos y el entierro se celebró bajo el púlpito del presbiterio de la iglesia burgalesa de los Mínimos, dando así cumplimiento al acuerdo del pintor con los Mínimos de Madrid ${ }^{18}$.

Una probable causa del afianzamiento del pintor en Burgos y de su desprendimiento de las casas de Madrid estriba en una curiosa nota del reverso del testamento de su padre fechado en 1652, en la que se indica que José Moreno tomó el hábito de San Benito en el monasterio de San Pedro de Cárdena ${ }^{19}$. Sin embargo no hay certeza sobre esta afirmación de los escribanos, pues, de haber sido cierta, lo más natural es que Moreno no hubiera muerto en el hospital de la Concepción. Además, en los libros de gradas (o de profesiones) del monasterio de Cárdena no consta ningún José Moreno en los años 1674-167720.

ISMAEL GUTIÉRREZ PASTOR Universidad Autónoma de Madrid

\footnotetext{
15 Palomino de Castro y Velasco, op. cit., edic. 1947, p. 976.

16 IBÁÑEz PÉREZ, Alberto C.: "Obras del pintor José Moreno en Quintanadueñas (Burgos)", en Boletín del Seminario de Arte y Arqueología, Valladolid, 1977, pp. 491-494. GutiérRez PASTOR, Ismael: "Iconografía de la Inmaculada Concepción en dos interpretaciones de José Moreno", en Estudios de Historia del Arte. Homenaje al profesor D. Alberto C. Ibáñez Pérez. Burgos, Universidad de Burgos, 2005, pp. 373-379.

${ }^{17}$ Gutiérrez PAstor, “José Moreno...., 2005, p. 70.

18 Resulta curioso, quizá fruto del azar y de la mucha devoción, que el retablo del Santo Cristo de Sangre de Torrijos esté coronado fuera de su estructura por un lienzo de la Virgen de la Soledad de la Victoria, dotado de un fastuoso marco del siglo XVIII. La Virgen de la Soledad fue la principal devoción del convento de los Franciscanos Mínimos de la Victoria de Madrid, a quien Moreno hizo donación de sus casas en la Puerta del Sol.

19 Ibidem, p. 69. Los documentos del Archivo Histórico Nacional de Madrid (sección Clero, libro 7765) están cargados de información suficiente como para resolver muchos aspectos de la biografía de Moreno. Sin embargo, fueron parcialmente utilizados por el marqués de Saltillo, quien con ello contribuyó a mantener los errores de Palomino.

${ }^{20}$ Así se deduce al menos del trabajo de Ernesto Zaragoza Pascual, "Libros de gradas de benedictinos profesos en monasterios burgaleses (1436-1833)”, en Studia Monastica, 31 (1989), vol. I, fasc. 2, pp. 283-295. El autor advierte del estado incompleto en el que los documentos de los monasterios burgaleses.
} 